\title{
Sd-Index of Another Case of Pericondensed Benzenoid Graphs G(m, n, k)
}

\begin{abstract}
Sufia Aziz
Department of Applied Sciences (Mathematics), Institute of Engineering and Technology, Devi Ahilya University, Indore 452017, M.P., India
\end{abstract}

Corresponding author: sufiaazizkhan@gmail.com

\begin{abstract}
In this paper, Sadhana (Sd) index of a pericondensed benzenoid graph consisting of three columns and having $m, n$, and $k$ hexagons (counted column wise), in armchair position, is computed in a simple way under different cases. Case for two rows and for three rows (zig-zag position) has already been established. It is concluded that the results obtained are same for both zig-zag and armchair positions.

Keywords: Topological index, Pericondensed Benzenoid graph, Sadhana (Sd) index Armchair position, Nanostructures

Mathematics Subject Classification: 05C10: Planar graphs; geometric and topological aspects of graph theory, 92E10: Molecular structure (graph-theoretic methods etc.).
\end{abstract}

A topological index is anumerical representative (real number)of the molecular graph. Since many years the topological indices like, Wiener-, Szeged -, PI-, Sd-, Balaban and Schultz's indices, have been used to model chemical, pharmaceutical and other properties of molecules.

Benzenoids are finite connected plane graphs with no cut-vertices ${ }^{[8]}$. Its types are phenylenes and their pericondensed benzenoid graph. These form base of nanostructures like, nanosheets, nanotubes, etc. In a nanosheet carbon atoms are densely packed in a honeycomb crystal lattice and when the sheet is rolled up along certain vectors, it gives rise to different types of nanotubes namely Armchair, Zig-zag and chiral. Ashrafi et al. in 2006, computed the PI index of Benzenoids ${ }^{[2]}$ as well as of some nanostructure ${ }^{[1]}$. In 2006, Deng et al. computed PI Index of Phenylenes ${ }^{[7]}$ and in 2008, PI indices of pericondensed Benzenoid graphs ${ }^{[6]}$. 


\section{Sadhana (Sd) Index:}

$\mathrm{In}^{[9]}$, the Sadhana $(\mathrm{Sd})$ index of a graph $G$ was first defined as:

$$
S d(G)=\sum\left(n_{e_{1}}+n_{e_{2}}\right)
$$

where, the sum of the edges is taken on both sides of elementary cut i.e., $\mathrm{n}_{\mathrm{e}_{1}}$ and $\mathrm{n}_{\mathrm{e}_{2}}$ are the number of edges on both sides of elementary cut and equidistant edges are not counted. $\operatorname{In}^{[3]}$ Sadhana (Sd) index for a sco bipartite graph $\mathrm{G}$ was mathematically defined as:

$$
\mathrm{S} d(G)=m(G) *(c(G)-1)
$$

where, $m(G)$ is the number of edges in $G$ and $c(G)$ is the number of orthogonal cuts in $G$.

Both PI-index and Sd-index being cyclic indices, Sd-index could be claimed to be applied to them too. Attempt towards this was made $\mathrm{in}^{[4]}$ for two rows of pericondensed benzenoid graph. And for three rows, in zig-zag position ${ }^{[5]}$. This paper extends the approach to compute Sadhana (Sd) index of three columns, in armchair form, of pericondensed benzenoid graph.

\section{MAIN RESULT}

In this section, $\mathrm{Sd}$-index of a pericondensed benzenoid graph $G(m, n, k)$, containing three columns, with $\mathrm{m}, \mathrm{n}$ and $\mathrm{k}$ hexagons (counted column wise) respectively, has been computed inarmchair positions, under different cases for $m, n, k$.

Theorem: Show that Sd index of pericondensed benzenoid graph $G(m, n, k)$, containing three columns, with $m, n$ and $k$ hexagons respectively, in armchair form is:

$$
\mathrm{Sd}(\mathrm{G})=\left\{\begin{array}{l}
3 \mathrm{n}^{2}+5 \mathrm{k}^{2}+3 \mathrm{~m}(\mathrm{n}+\mathrm{k})+8 \mathrm{nk}+17 \mathrm{n}+25 \mathrm{k}+12 \mathrm{~m}+20, \mathrm{~m}<\mathrm{n} \text { and } \mathrm{n}=\mathrm{k} \\
8 \mathrm{~m}^{2}+3 \mathrm{n}^{2}+11 \mathrm{mn}+37 \mathrm{~m}+17 \mathrm{n}+20, \mathrm{~m}=\mathrm{n}=\mathrm{k} \\
10 \mathrm{~m}^{2}+6 \mathrm{mn}+6 \mathrm{mk}+23 \mathrm{~m}+9 \mathrm{n}+9 \mathrm{k}+12, \mathrm{~m}>\mathrm{n} \geq \mathrm{k} \\
10 \mathrm{k}^{2}+6 \mathrm{mk}+6 \mathrm{nk}+23 \mathrm{k}+9 \mathrm{n}+9 \mathrm{~m}+12, \mathrm{~m} \leq \mathrm{n}<\mathrm{k} \\
10 \mathrm{~m}^{2}+6 \mathrm{mn}+6 \mathrm{mk}+30 \mathrm{~m}+12 \mathrm{n}+12 \mathrm{k}+20, \mathrm{n}<\mathrm{m}, \mathrm{k} \text { and } \mathrm{m}>\mathrm{k} \\
10 \mathrm{n}^{2}+6 \mathrm{mn}+6 \mathrm{n}+12 \mathrm{~m}+30 \mathrm{n}+12 \mathrm{k}+20, \mathrm{~m}<\mathrm{n}, \mathrm{k} \text { and } \mathrm{n}>\mathrm{k}
\end{array}\right.
$$

Proof: Let $G(m, n, k)$ be a pericondensed benzenoid graph (armchair) containing three columns, with $m$, $n$ and $k$ hexagons. Then following cases are possible:

Case (i): Whenm $<\mathbf{n}$ and $\mathbf{n}=\mathbf{k}$ (Fig. 1).

On generalizing the sequence of results, by varying the value of $\mathrm{m}, \mathrm{n}$ and $\mathrm{k}$ in this case, we obtain a general formula for number of edges as $\mathrm{m}(\mathrm{G})=3 \mathrm{~m}+3 \mathrm{n}+5 \mathrm{k}+5$ and number of orthogonal cuts as $\mathrm{c}(\mathrm{G})=\mathrm{n}+\mathrm{k}+5$. Therefore using equation (2), we get,

$\mathrm{Sd}(\mathrm{G})=(3 \mathrm{~m}+3 \mathrm{n}+5 \mathrm{k}+5) *(\mathrm{n}+\mathrm{k}+5-1)$

$=3 n^{2}+5 k^{2}+3 m(n+k)+8 n k+17 n+25 k+12 m+20$. 


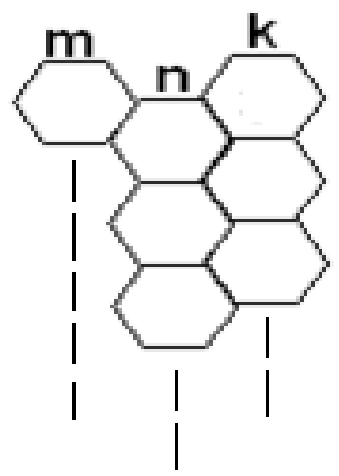

Fig. 1: Apericondensed benzenoid graph $G(m, n, k)$, when $m<n$ and $n=k$

Case (ii): When $\mathbf{m}=\mathbf{n}=\mathbf{k}$ (Fig. 2).

Again generalizing the sequence of results, by varying the value of $m, n$ and $k$ in this case, we obtain a general formula for number of edges as $\mathrm{m}(\mathrm{G})=8 \mathrm{~m}+3 \mathrm{n}+5$ and number of orthogonal cuts as $\mathrm{c}(\mathrm{G})=\mathrm{m}+$ $\mathrm{n}+5$. From equation (2), we get,

$\mathrm{Sd}(\mathrm{G})=(8 \mathrm{~m}+3 \mathrm{n}+5) *(\mathrm{~m}+\mathrm{n}+5-1)$

$=8 m^{2}+3 n^{2}+11 m n+37 m+17 n+20$.

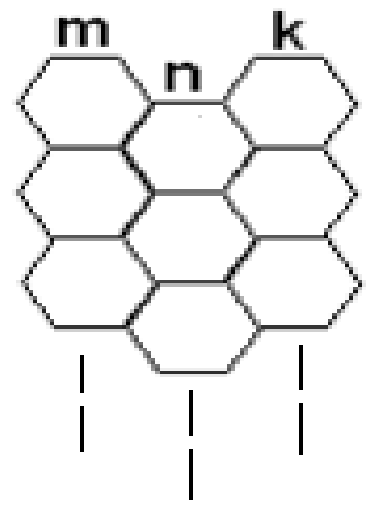

Fig. 2: Apericondensed benzenoid graph $\mathrm{G}(\mathrm{m}, \mathrm{n}, \mathrm{k})$, when $\mathrm{m}=\mathrm{n}=\mathrm{k}$

Case (iii): When $\boldsymbol{m}>\boldsymbol{n} \geq \boldsymbol{k}$ (Fig. 3).

On generalizing the sequence of results, by varying the value of $m, n$ and $k$ in this case, we obtain a general formula for number of edges as $m(G)=5 m+3 n+3 k+4$ and number of orthogonal cuts as $c(G)$ $=2 \mathrm{~m}+4$. From equation $(2)$, we get,

$\mathrm{Sd}(\mathrm{G})=(5 \mathrm{~m}+3 \mathrm{n}+3 \mathrm{k}+4) *(2 \mathrm{~m}+4-1)$

$=10 m^{2}+6 m n+6 m k+23 m+9 n+9 k+12$. 


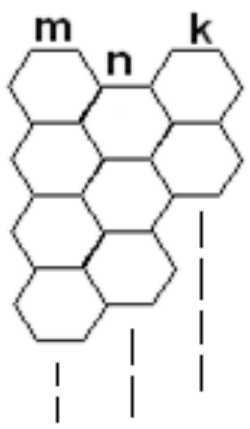

(a)

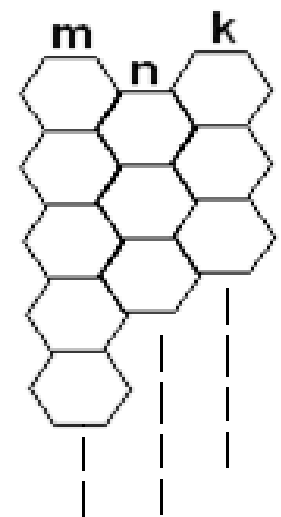

(b)

Fig. 3: Apericondensed benzenoid graph $G(m, n, k)$, when (a) $m>n=k,(b) m>n>k$

Case (iv): When $\boldsymbol{m} \leq \boldsymbol{n}<\boldsymbol{k}$ (Fig. 4).

Generalizing the sequence of results, by varying the value of $m, n$ and $k$ in this case, we obtain a general formula for number of edges as $\mathrm{m}(\mathrm{G})=3 \mathrm{~m}+3 \mathrm{n}+5 \mathrm{k}+4$ and number of orthogonal cuts as $\mathrm{c}(\mathrm{G})=2 \mathrm{k}$ +4 . From equation (2), we get,

$\mathrm{Sd}(\mathrm{G})=(3 \mathrm{~m}+3 \mathrm{n}+5 \mathrm{k}+4) *(2 \mathrm{k}+4-1)$

$=10 \mathrm{k}^{2}+6 \mathrm{mk}+6 \mathrm{nk}+23 \mathrm{k}+9 \mathrm{n}+9 \mathrm{k}+12$.

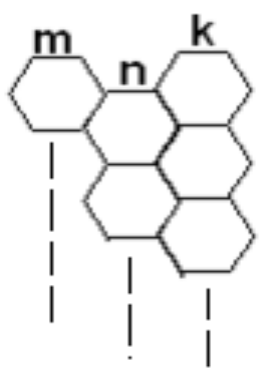

(a)

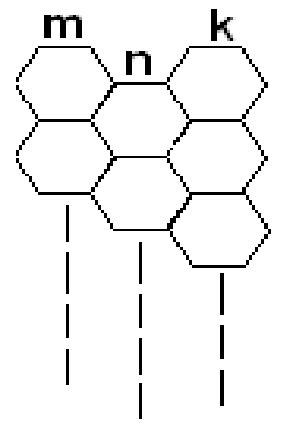

(b)

Fig. 4: Apericondensed benzenoid graph $G(m, n, k)$, when (a) $m<n<k$, (b) $m=n, n<k$

Case (v): When $\boldsymbol{n}<\boldsymbol{m}$, $\boldsymbol{k}$ and $\boldsymbol{m}>\boldsymbol{k}$ (Fig. 5).

Generalizing the sequence of results, by varying the value of $m, n$ and $k$ in this case, we obtain a general formula for number of edges as $\mathrm{m}(\mathrm{G})=5 \mathrm{~m}+3 \mathrm{n}+3 \mathrm{k}+5$ and number of orthogonal cuts as $\mathrm{c}(\mathrm{G})=2 \mathrm{~m}$ +5 . From equation (2), we get,

$$
\begin{aligned}
& \mathrm{Sd}(\mathrm{G})=(5 \mathrm{~m}+3 \mathrm{n}+3 \mathrm{k}+5) *(2 \mathrm{~m}+5-1) \\
& =10 \mathrm{~m}^{2}+6 \mathrm{mn}+6 \mathrm{mk}+30 \mathrm{~m}+12 \mathrm{n}+12 \mathrm{k}+20
\end{aligned}
$$




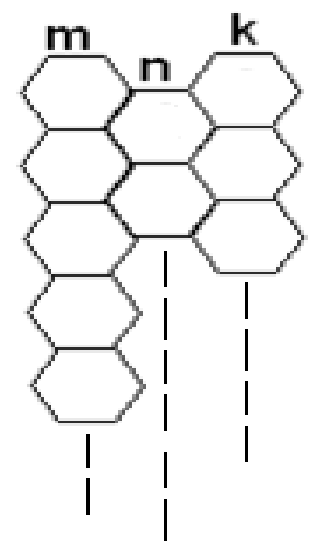

Fig. 5: Apericondensed benzenoid graph $\mathrm{G}(\mathrm{m}, \mathrm{n}, \mathrm{k})$, when $\mathrm{n}<\mathrm{m}$, $\mathrm{k}$ and $\mathrm{m}>\mathrm{k}$

Case (vi): When $\boldsymbol{m}<\boldsymbol{n}, \boldsymbol{k}$ and $\boldsymbol{n}>\boldsymbol{k}$ (Fig. 6).

Generalizing the sequence of results, by varying the value of $m, n$ and $k$ in this case, we obtain a general formula for number of edges as $\mathrm{m}(\mathrm{G})=3 \mathrm{~m}+5 \mathrm{n}+3 \mathrm{k}+5$ and number of orthogonal cuts as $\mathrm{c}(\mathrm{G})=2 \mathrm{n}+$ 5. From equation (2), we get,

$\mathrm{Sd}(\mathrm{G})=(3 \mathrm{~m}+5 \mathrm{n}+3 \mathrm{k}+5) *(2 \mathrm{n}+5-1)$

$=10 n^{2}+6 m n+6 n k+12 m+30 n+12 k+20$.

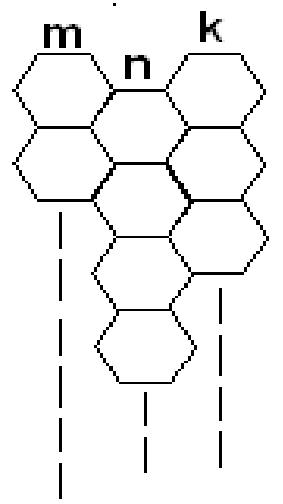

Fig. 6: Apericondensed benzenoid graph $G(m, n, k)$, when $m<n, k$ and $n>k$

All the results obtained in various cases have been verified by computing Sd-index, in each case, of small structures. Hence, they hold in general. Hence proved.

\section{CONCLUSION}

The results obtained for Sadhana (Sd) index of three columns, in armchair form,were same as in zig-zag form for three rows ${ }^{[9]}$. This shows that the main result is a general result for pericondensed benzenoid 
graph G(m, n, k) (zig-zag and armchair both). It can be extended to obtain a general form (more number of rows/columns), which is an open problem. The results can also be extended to computing Sadhana (Sd) index of other nanostructures.

\section{REFERENCES}

1. Ashrafi, A.R. and Vakili-Nezhaad, G.R. 2006. Computing PI Index of some chemical graphs related to nanostructures, Journal of Physics: Conference series, 29: 181-184.

2. Ashrafi, A.R. and Loghman, A. 2006. PI Index of some Benzenoid Graph, J. Chil. Chem. Soc., 51: 968-970.

3. Aziz, S., Manikpuri, A.D., Khadikar, P.V. and John, P.E. 2009. Sadhana: A new Topological Index for Carbon Nanotubes (CNT'S), J. of Comp. and Theo. Nanosciences, 6: 673-675.

4. Aziz, S. Computing Sd-Index of Some Benzenoid Graphs, International J. of Mathematical Sciences, (Accepted for publication in July-Dec'18 issue).

5. Aziz, S. 2018. Sadhana (Sd) Index of Pericondensed Benzenoid Graphs G(m, n, k), Journal of Interdisciplinary Mathematics, (communicated Sep. 2018).

6. Deng, H. and Chen, S. 2008. PI Indices of Pericondensed Benzenoid Graphs, J. Math. Chem., 43: 243-250.

7. Deng, H., Chen, S. and Zhang, J. 2006. PI Index of Phenylenes, J. Math. Chem., 41: 63-69.

8. Gutman, I. and Cyvin, S.J. 1989. Introduction to the Theory of Benzenoidhydrocarons; Springer-Verlag, Berli.

9. Khadikar, P.V., Mandloi, D. and Karmarkar, S. 2006. Sadhana (Sd) A new cyclic index: QSPR / QSAR studies of linear polyacenes, Bioinfo. Trends, 1: 51-63. 